\title{
Contamination Control and RDD Response Overview
}

Bryce J Marsh, Christopher P Oertel, Benjamin W Walker

February 2019

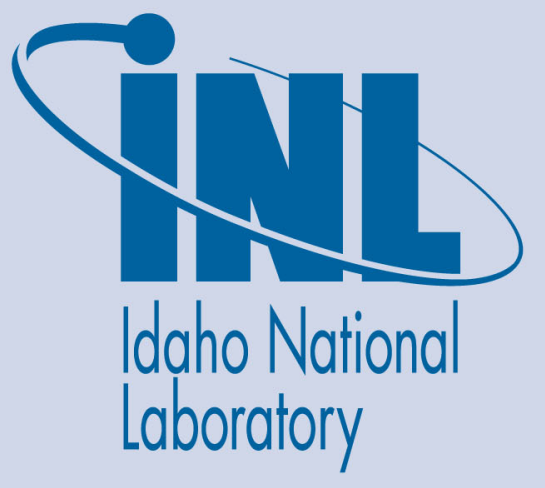

The INL is a U.S. Department of Energy National Laboratory operated by Battelle Energy Alliance 


\title{
Contamination Control and RDD Response Overview
}

\author{
Bryce J Marsh, Christopher P Oertel, Benjamin W Walker
}

February 2019

Idaho National Laboratory Idaho Falls, Idaho 83415

http://www.inl.gov

Prepared for the U.S. Department of Energy

National Nuclear Security Administration

Under DOE Idaho Operations Office

Contract DE-AC07-05ID14517 


\section{Contamination Control \& RDD Response Overview}

Advanced Radiological Detection Training WMD-Civil Support Team, 2019

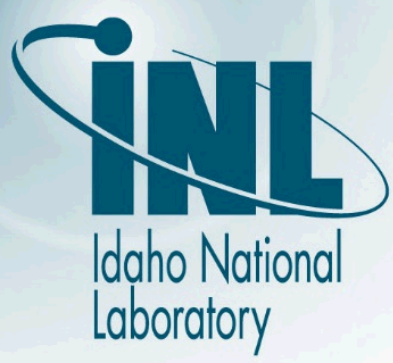




\section{Lesson Objectives}

1. Explain the differences between radiation and contamination

2. Identify types and levels of contamination

3. Identify sources and indicators of contamination

4. Discuss methods to control contamination

5. Discuss DHS S\&T response guidance post RDD

6. Discuss the 10 Point Survey method 


\section{Radiation and Contamination}

- Radiation

- Energy emitted from an unstable, radioactive material

- Contamination

- Radioactive material in the form of finely divided particles that can be easily spread
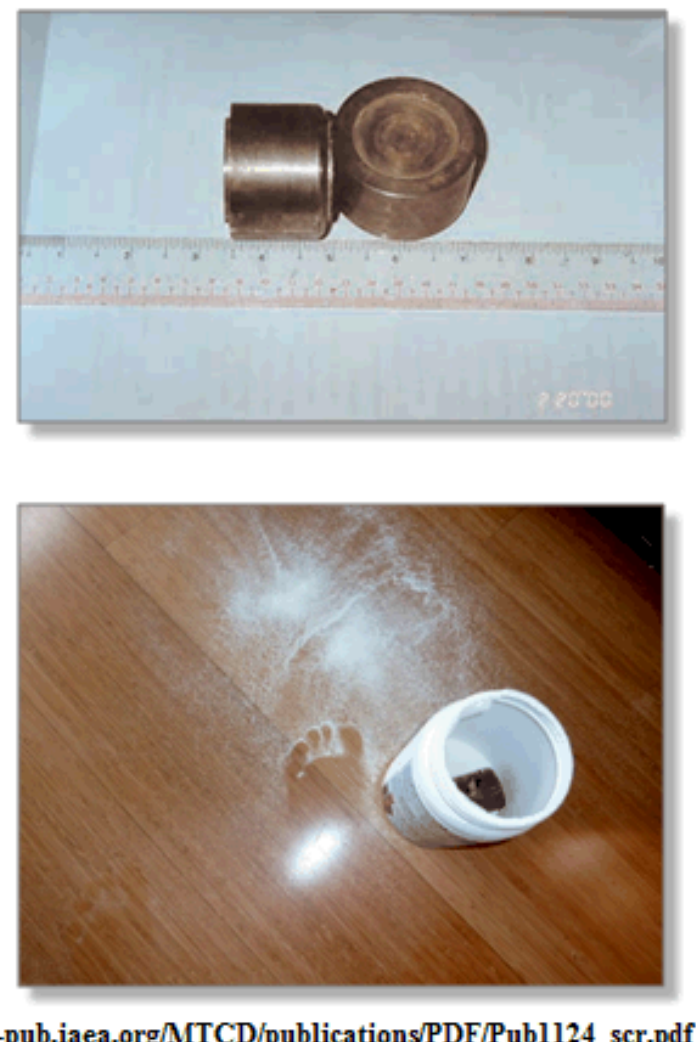


\section{Contamination Types}

- Fixed

- Cannot be easily removed

- May be released by buffing, grinding, chemical etching, etc.

- Removable

- Can be easily removed/transferred by casual contact, wiping, brushing, washing, air movement, etc.

- Airborne

- Contamination suspended in air 


\section{Contamination Control}

- Understand the conditions through surveys

- Direct measurements

- Swipes or wipes

- Keep it off your skin/personal clothing

- Wear appropriate PPE

- Avoid contacting contaminated surfaces

- Avoid ingesting or inhaling it

- Don't touch your face/head

- Respiratory protection

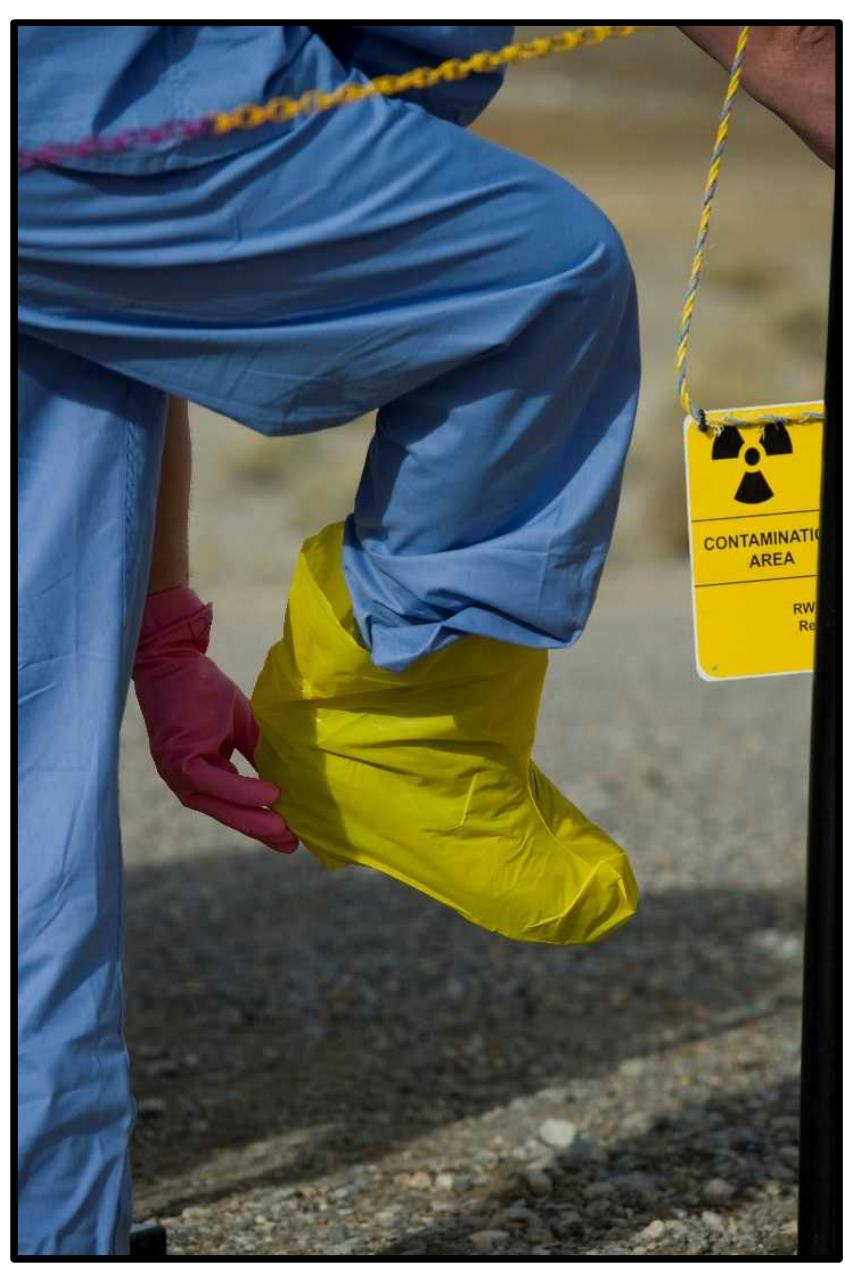




\section{Contamination Control}

- Minimize cross-contamination

- Use laydown area (plastic or other material)

- Wrap equipment/tools prior to entry

- Frequent glove changes

- Avoid contact with uncontaminated equipment

- Monitor yourself and equipment prior to leaving area

- "Frisking"

- Decontaminate if necessary, or control contaminated items/materials

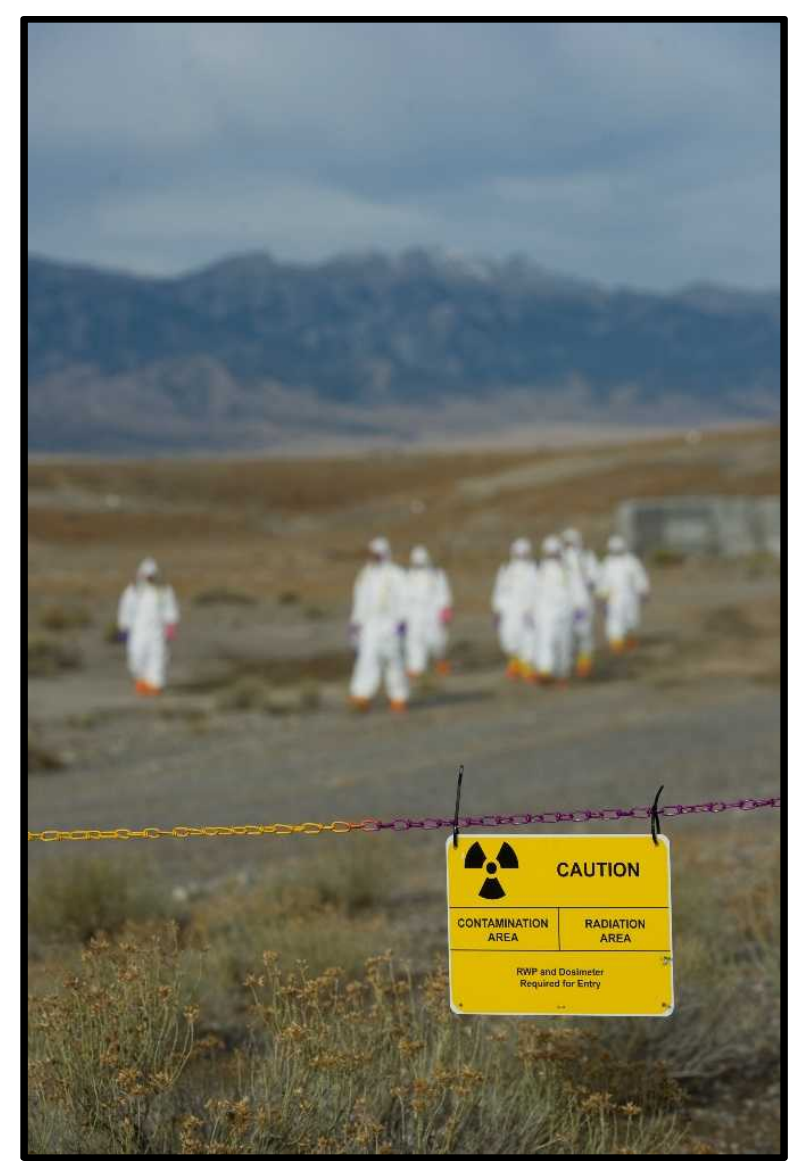

- Dry vs. wet 


\section{Contamination}

- $\alpha$-Contamination is indicated if any increase in count rate is seen for Alpha contamination surveys.

- $\beta, \gamma$ - Contamination is indicated if count rate increases to 100 CPM above (or $2 \mathrm{X}$ ) background for Beta/Gamma contamination surveys.

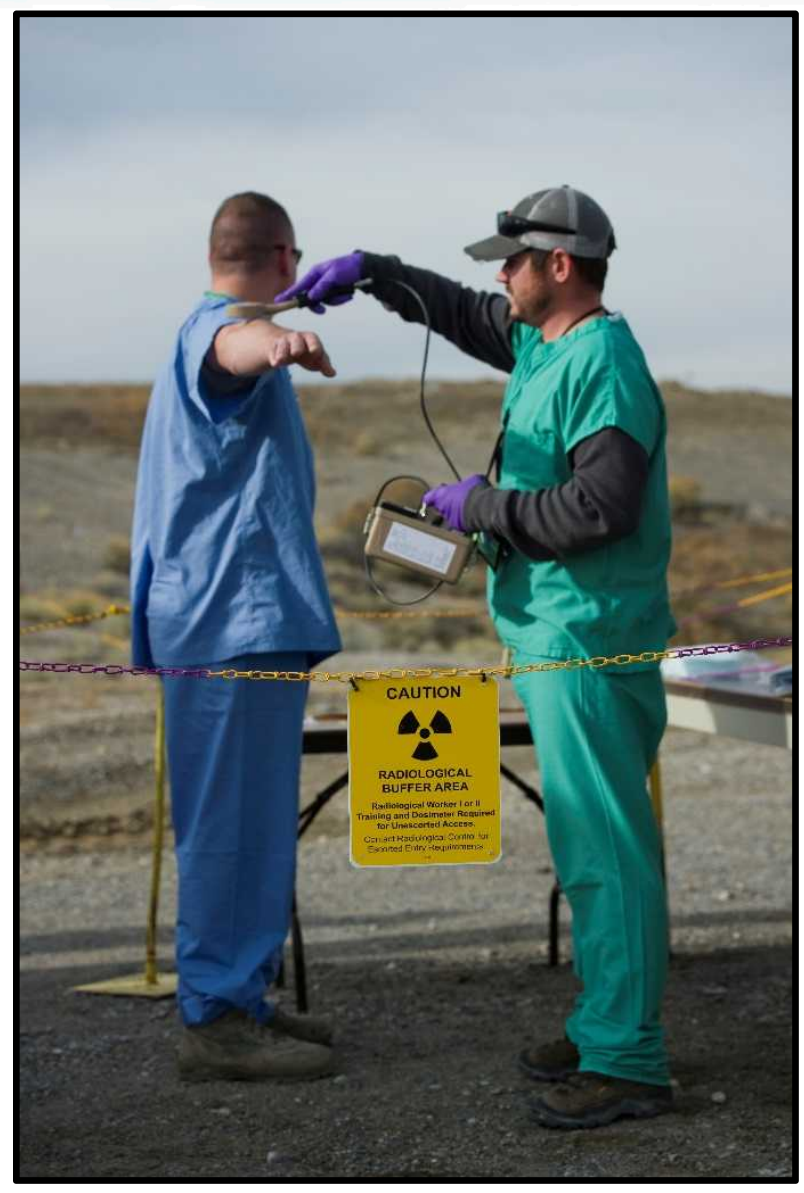

DHS RDD Response Guidance: contamination safety boundary can be set at levels that exceed $60,000 \mathrm{dpm} / \mathrm{cm}^{2}$ at ground level for $\beta$ and $\gamma$, or 6,000 $\mathrm{dpm} / \mathrm{cm}^{2}$ for $\alpha$ 


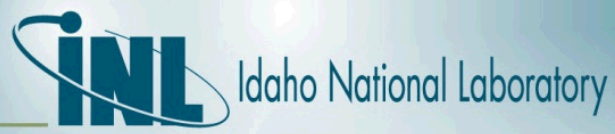

\section{DA PAM 385-24}

In the absence of other regulatory or advisory guidance, a surface is contaminated if either the removable or total radioactivity is above the levels in table 5-2.

\begin{tabular}{|c|c|c|}
\hline RadionuclideGroups $^{(\mathbf{a})}$ & $\begin{array}{l}\text { Screening Levels } \\
\text { (S.I. Units) }^{(\mathrm{b})}\end{array}$ & $\begin{array}{c}\text { Surface } \\
\text { Screening } \\
\text { (Conventional } \\
\text { Units) }\end{array}$ \\
\hline & $\left(\mathrm{Bq} / \mathrm{cm}^{2} \text { or } \mathrm{Bq} / \mathrm{g}\right)^{(\mathrm{c})}$ & (dpm/100 cm²) \\
\hline $\begin{array}{l}\text { Group } 1 \\
\text { Radium, Thorium, and Transuranics: }{ }^{210} \mathrm{Po},{ }^{210} \mathrm{~Pb},{ }^{228} \\
\mathrm{Ra},{ }^{228} \mathrm{Ra}^{228} \mathrm{Th},{ }^{230} \mathrm{Th},{ }^{232} \mathrm{Th},{ }^{237} \mathrm{~Np},{ }^{239} \mathrm{Pu},{ }^{240} \mathrm{Pu}^{241} \\
\mathrm{Am},{ }^{244} \mathrm{Cm} \text {, and associated decay chains }{ }^{(d)} \text {, and other- } \\
\mathrm{s}^{(\mathrm{a})}\end{array}$ & 0.1 & 600 \\
\hline 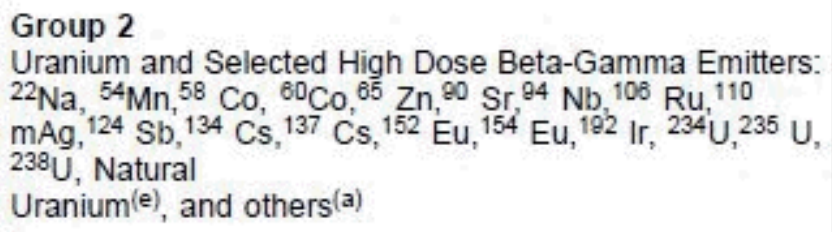 & 1 & 6,000 \\
\hline $\begin{array}{l}\text { Group } 3 \\
\text { General Beta-Gamma Emitters: }{ }^{24} \mathrm{Na}, 36 \mathrm{Cl},{ }^{50} \mathrm{Fe} \text {, } \\
{ }^{109} \mathrm{Cd},{ }^{131} \mathrm{I},{ }^{129},{ }^{144} \mathrm{Ce},{ }^{198} \mathrm{Au},{ }^{241} \mathrm{Pu} \text {, and others }(\mathrm{a})\end{array}$ & 10 & 60,000 \\
\hline $\begin{array}{l}\text { Group } 4^{(\mathrm{f})} \\
\text { Other Beta-Gamma Emitters: } \\
{ }^{3} \mathrm{H}^{14}{ }^{14} \mathrm{C}^{32} \mathrm{P},{ }^{35} \mathrm{~S},{ }^{45} \mathrm{Ca},{ }^{51} \mathrm{Cr},{ }^{55} \mathrm{Fe},{ }^{63} \mathrm{Ni},{ }^{89} \mathrm{Sr},{ }^{99} \mathrm{Tc},{ }^{111} \\
\text { In, }{ }^{125} \mathrm{I},{ }^{147} \mathrm{Pm} \text {, and others }{ }^{(\mathrm{a})}\end{array}$ & 100 & 600,000 \\
\hline
\end{tabular}




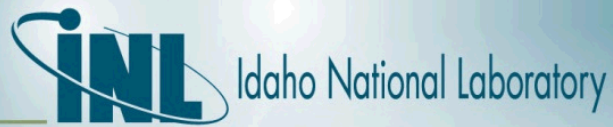

\section{Contamination}

\section{Counts}

\section{Efficiency}

\section{$=\mathrm{DPM}$}

\section{CPM}

.10
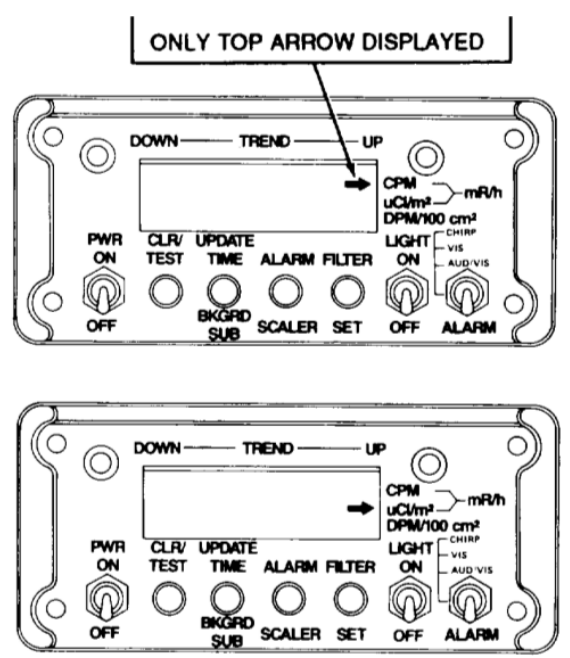

ALPHA PROBE CONNECTED ANY ONE (BUT NOT MORE

THAN ONE) OF THE ARROWS DISPLAYED.

$=1000 \mathrm{DPM}$ 


\section{PDR 77 Efficiency}

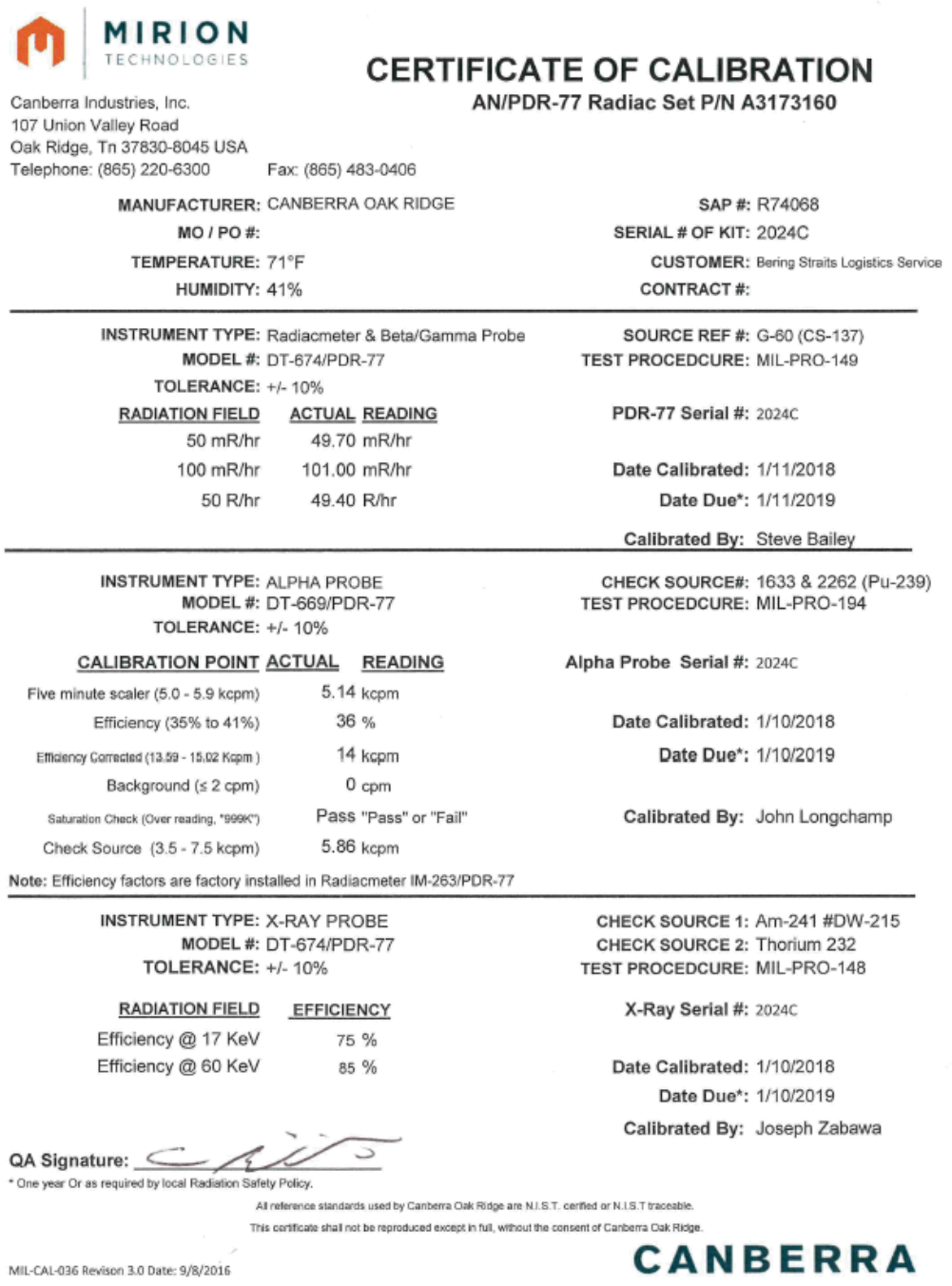




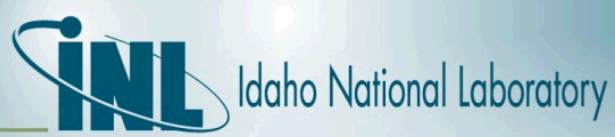

\section{Guidelines For Frisking}

- Survey hands first

ACCEPTABLE PERSONNEL FRISK

- Distance and rate

$-\beta$ Y: within $1 / 2 ", 2$ "'/second

$-\alpha$ : within $1 / 4 ", 1 / 2 " /$ second

- For increased activity

- Pause 5-10 seconds to verify contamination

- If contaminated:
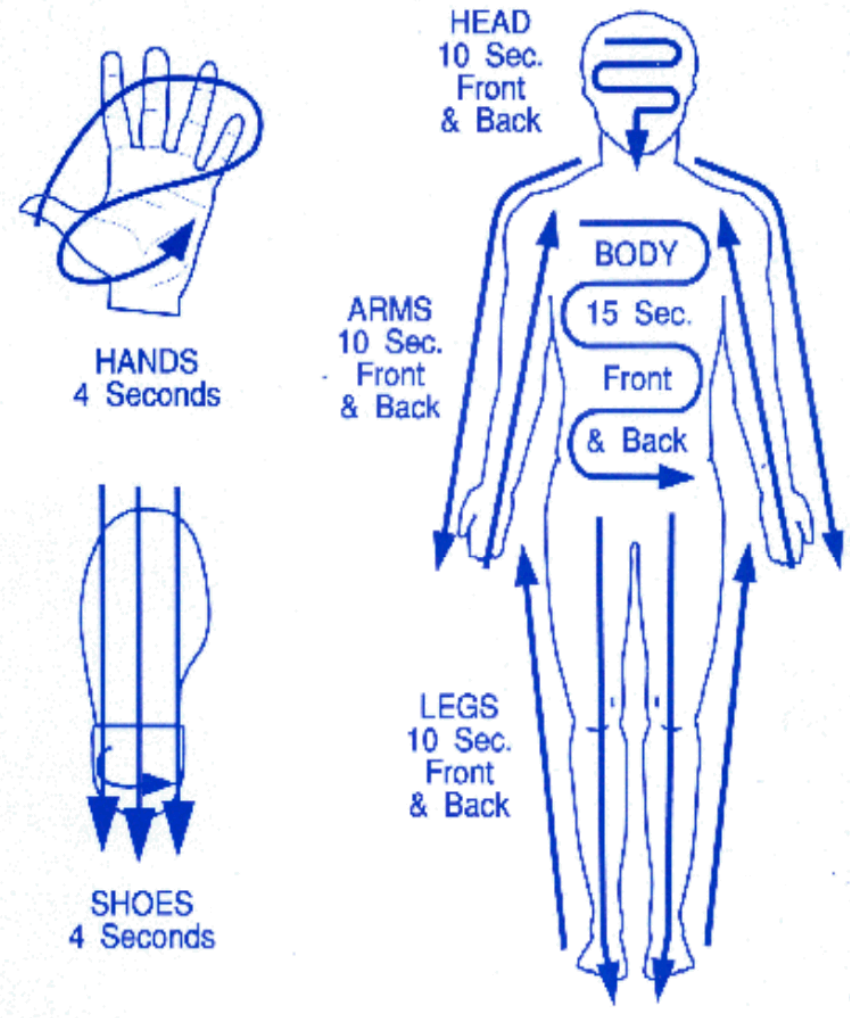

- Remain in the area

- Contact Rad Con

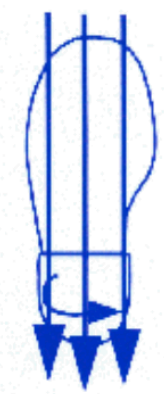

SHOES

4 Seconds

A Whole Body Frisk Requires At Least (2) To (3) Minutes (2" To 3" Per Second) Slow Movement Of Frisker Probe Within 1/2 Inch Of Surface Is Required

- Minimize spread of contamination 


\section{Personnel Decontamination}

- If contamination is present on an individual removal is normally accomplished using mild soap and lukewarm water on the affected area

- If contamination can not be removed secure the affected area with a secure wrapping and transport the person to a medical treatment facility

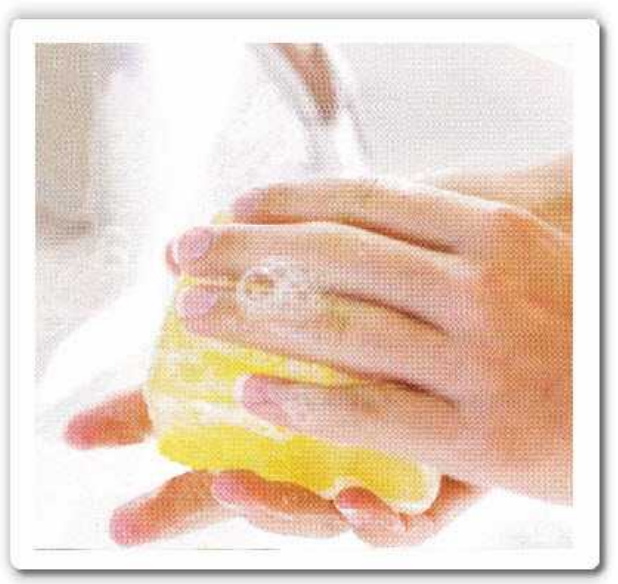




\section{Case Study: Personnel Contamination}

At 15:20 a researcher working in the RCL Lab B-7 detected contamination on their thumb and index finger of the left hand. The facility HPT was immediately notified and confirmed initial contamination levels of 6,000 dpm beta/gamma and 3,000 dpm alpha on the researcher's left hand. The researcher was taken to the EBR-II decon facility where the hand was resurveyed showing contamination levels of $12,000 \mathrm{dpm}$ beta/gamma and $8,000 \mathrm{dpm}$ alpha. These contamination levels were significantly higher than the initial survey. After approximately $\mathbf{2 0}$ minutes of decon efforts the hand was resurveyed showing 6,000 dpm beta/gamma and 2,200 dpm alpha on the first crease of the middle finger. With Rad engineering support a glove was placed over the left hand to allow the hand to sweat to assist with releasing the contamination from the skin. The glove was removed approximately 15 minutes later and the hand was deconned and showed 1,000 dpm beta/gamma and no detectable alpha. Another glove was placed on the hand to allow for the hand to continue to sweat to release the contamination. Decontamination efforts continued for several hours. The researcher's hand was successfully decontaminated. 


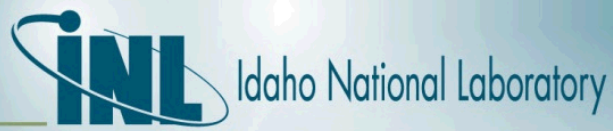

\section{Battle Drills: What is your plan?}

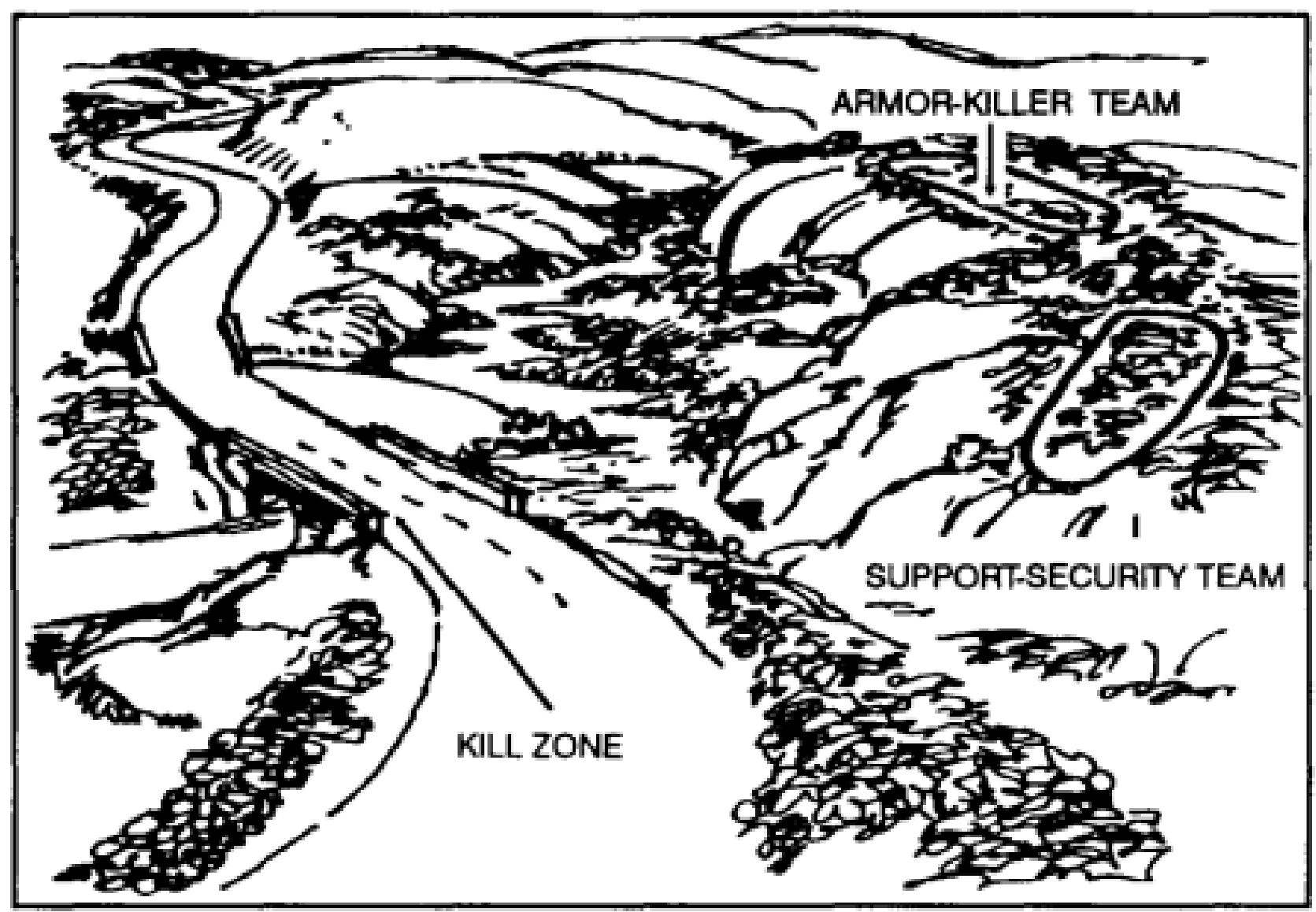

Figure 3-16. Antiarmor ambush. 


\section{Boston Bombing}

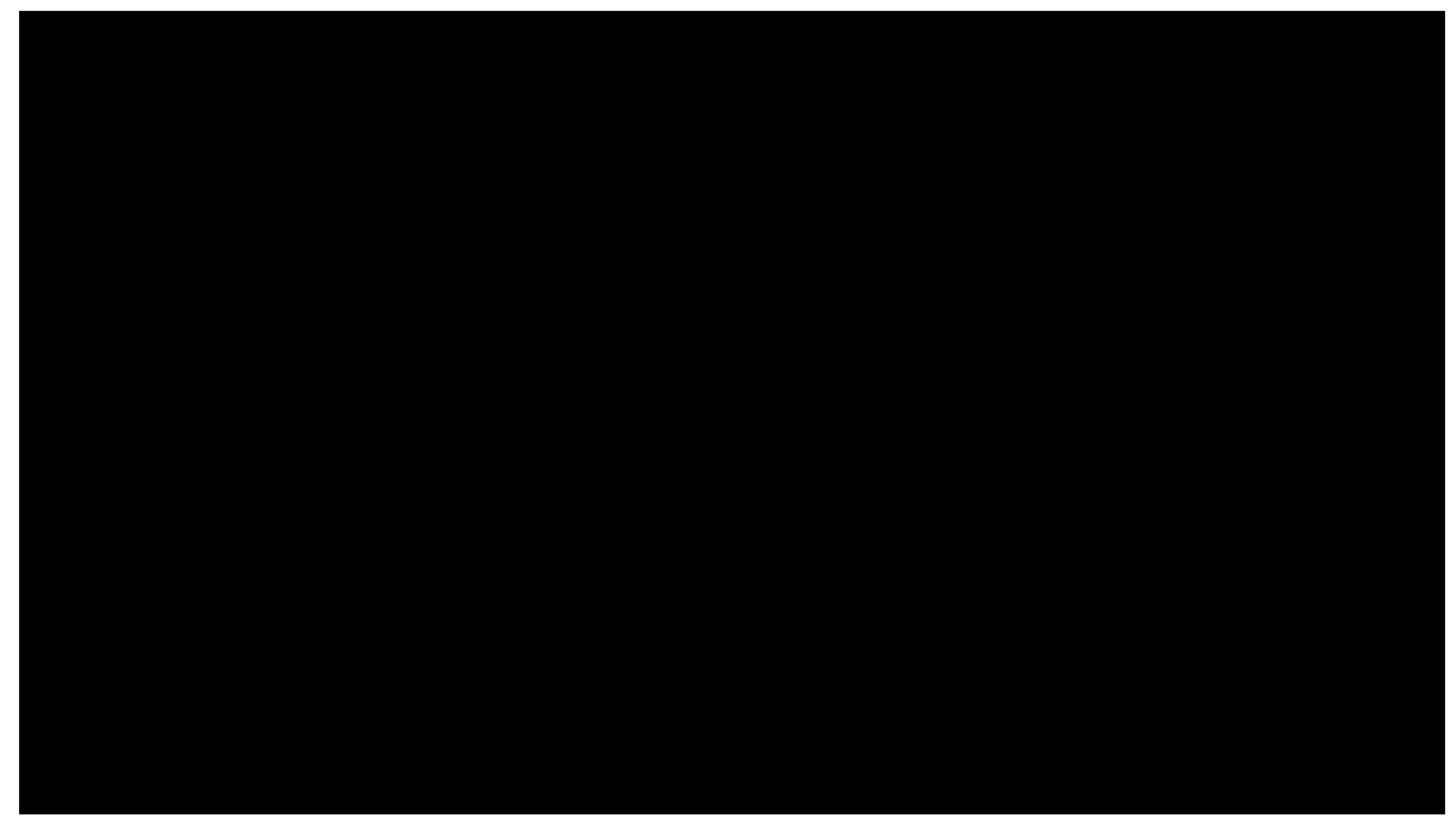




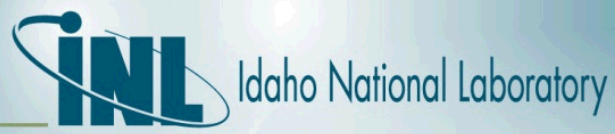

\section{Radiological Dispersal Device Detonation is a Contamination Event}

- Three teams will make entry into a contamination zone with specific tasks to conduct Phase I survey operations

- DHS S\&T ConOp

- Avoid contamination and follow all instructions from RadCon as per the RPP

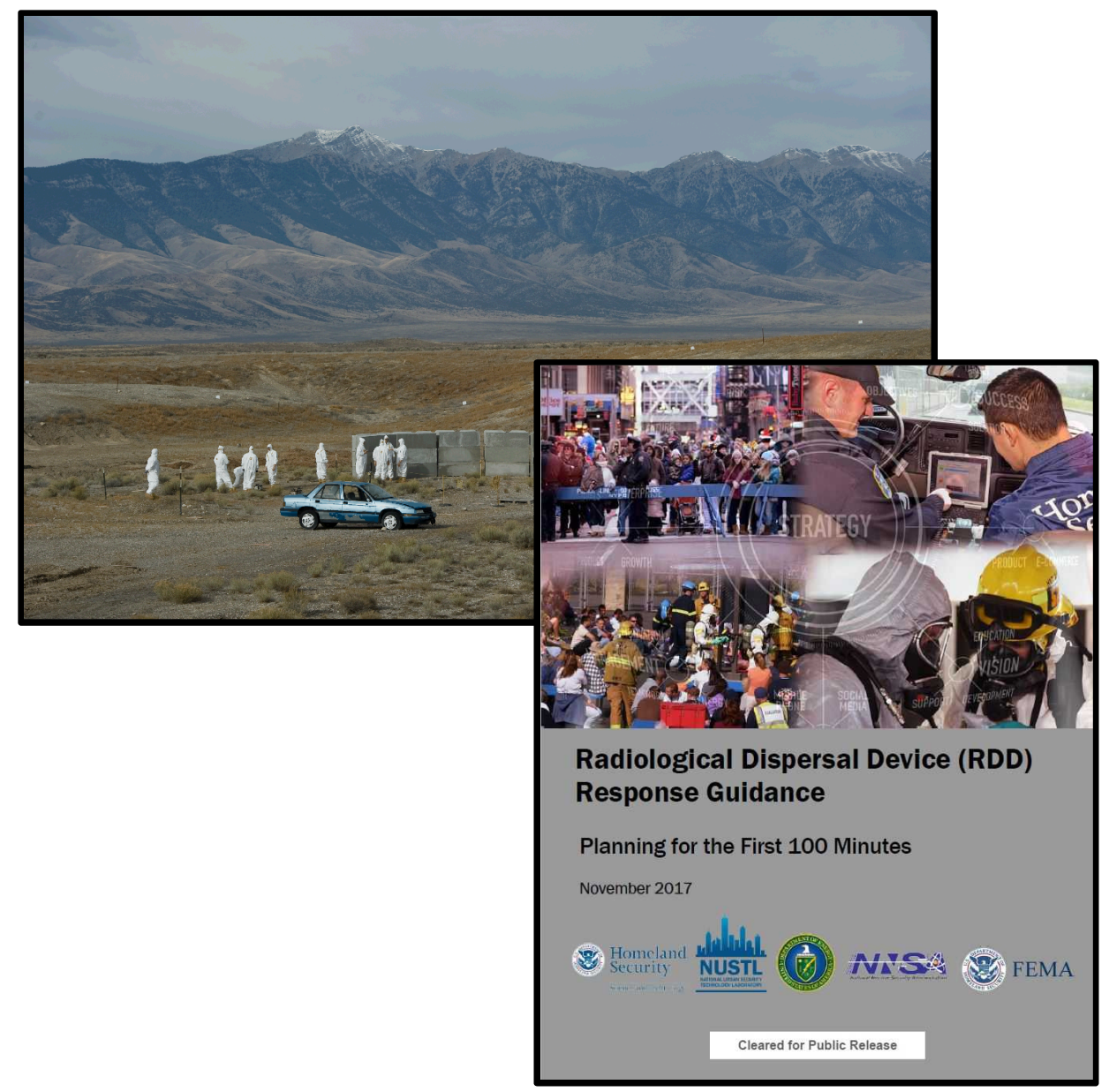




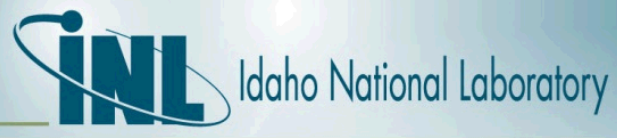

\section{Our Goal is to Dispel Misinformation \& Challenge Bad Assumptions}

Misinformation

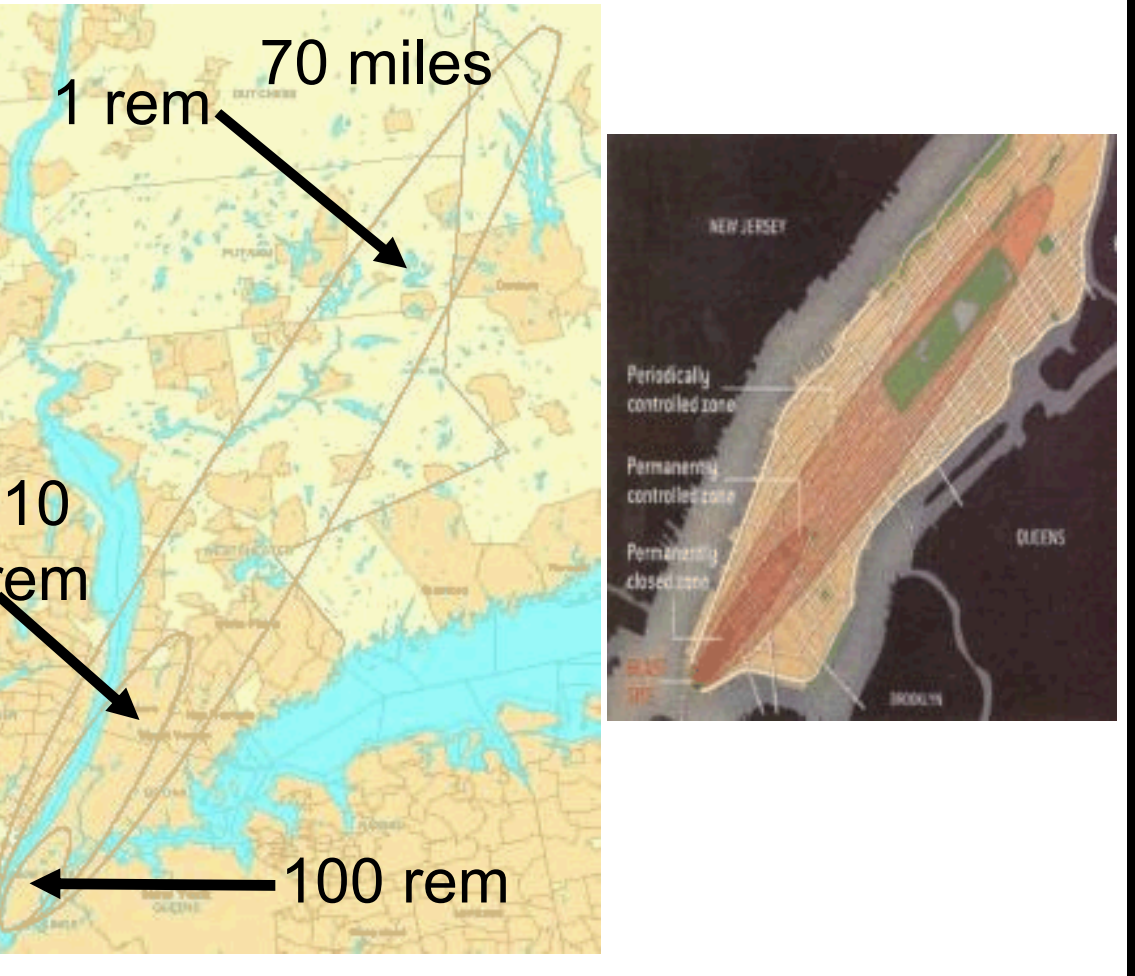

From DOE experiments

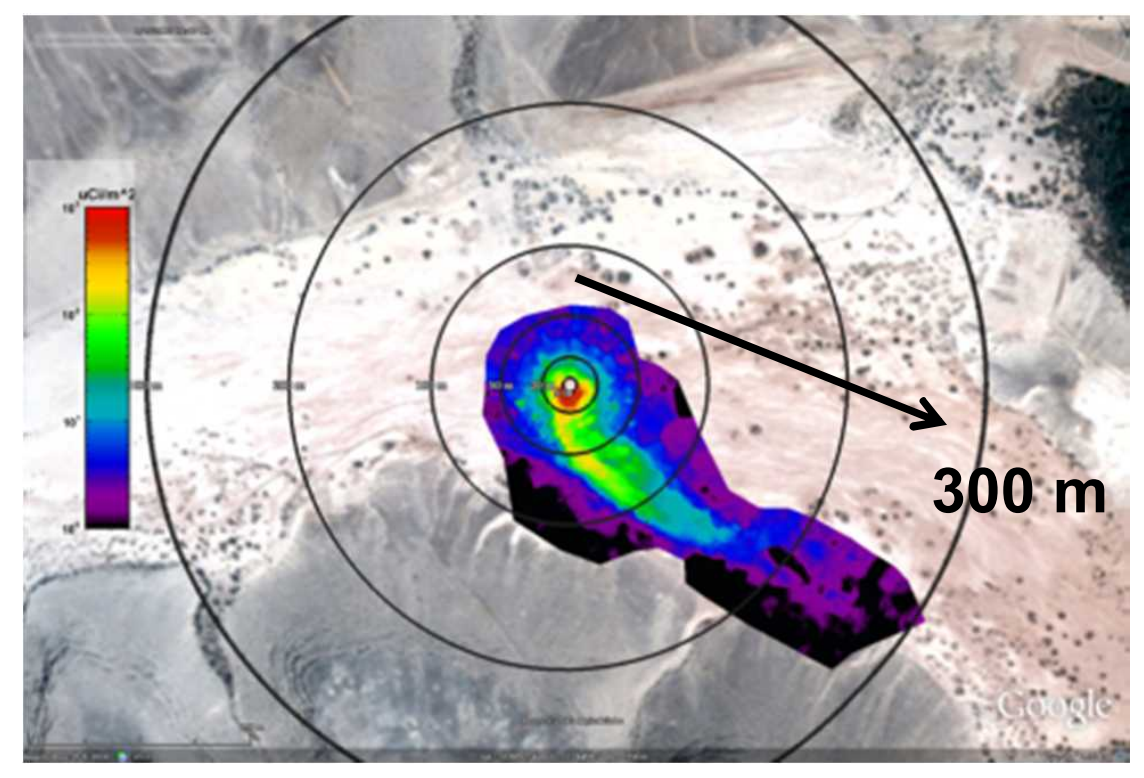

Federation of American Scientists. Dirty bomb: Response to Threat, FAS Public Interest Report, J. Federal. Am. Scient. 55(2), 1-10 


\section{Factors that Affect Dispersion}

"RDDs, or dirty bombs are devices that disperse radioactive materials. They can take many forms - from containers of radioactive materials wrapped around with conventional explosives, to aerosolized materials sprayed using conventional equipment, and to manual dispersion of fine powder.."

Final Presentation: Dhiren Barot

- Source Material, Form

- Energetic Material

- Device, "BBs or Smoke?"

- Fireball interaction with surface, ground zero hotspot vs down wind plume

- Environment, Micro Weather 


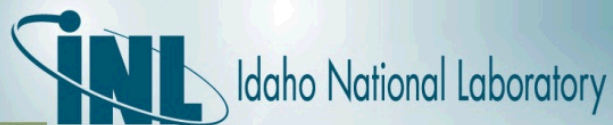

\section{Particle/Frag Size, HE amount/location determine deposition pattern - size matters}

Fireball Interaction Area

Large Particles ( 100-500 $\mu \mathrm{m}$ )

aA Ballistic Fragments $(>1 \mathrm{~cm})$

Impact of particle/frag size on deposition

Downwind Fallout (small particles)

Direction of Contamination

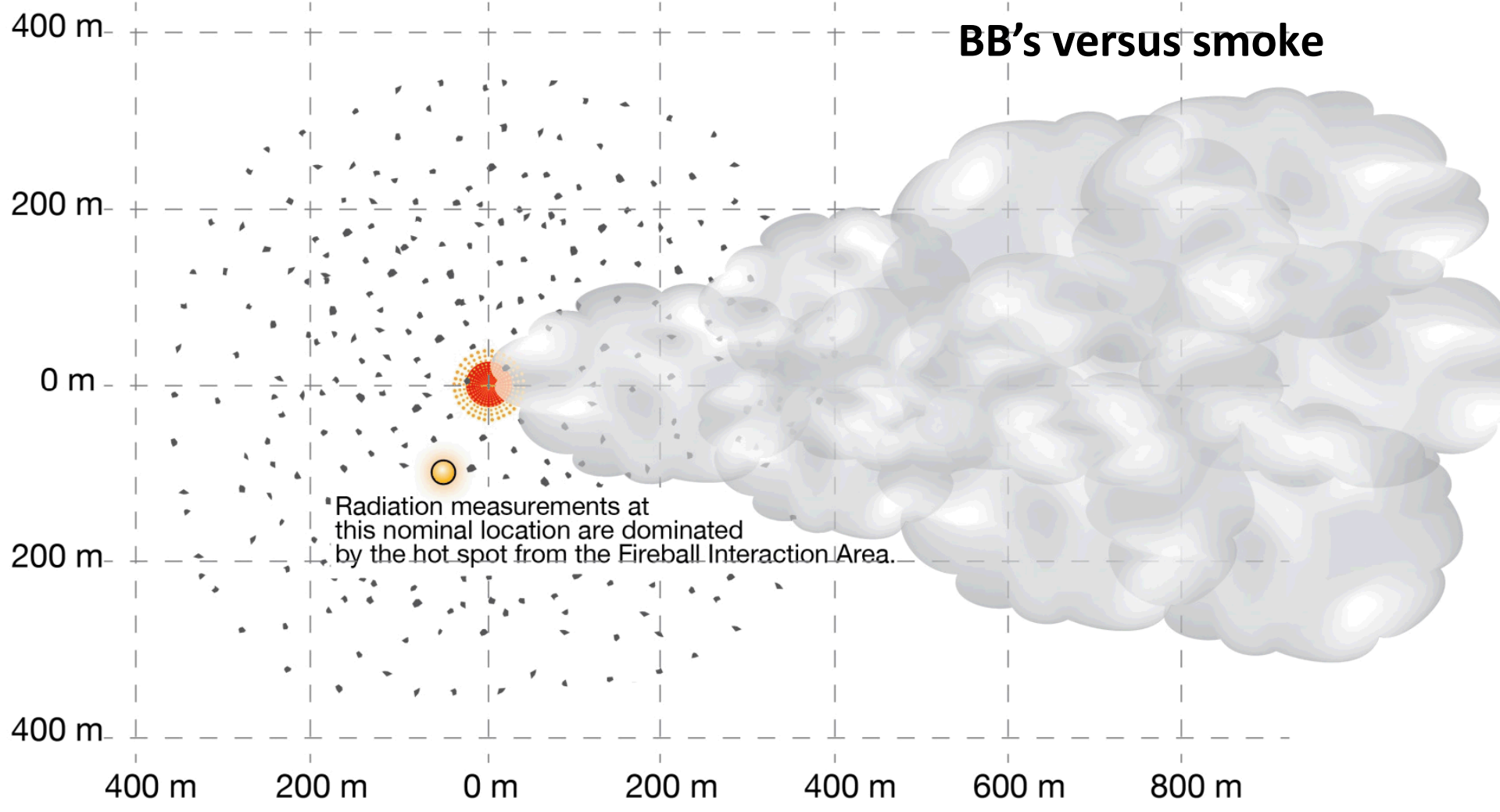




\section{Detonation - High-Speed Imagery}

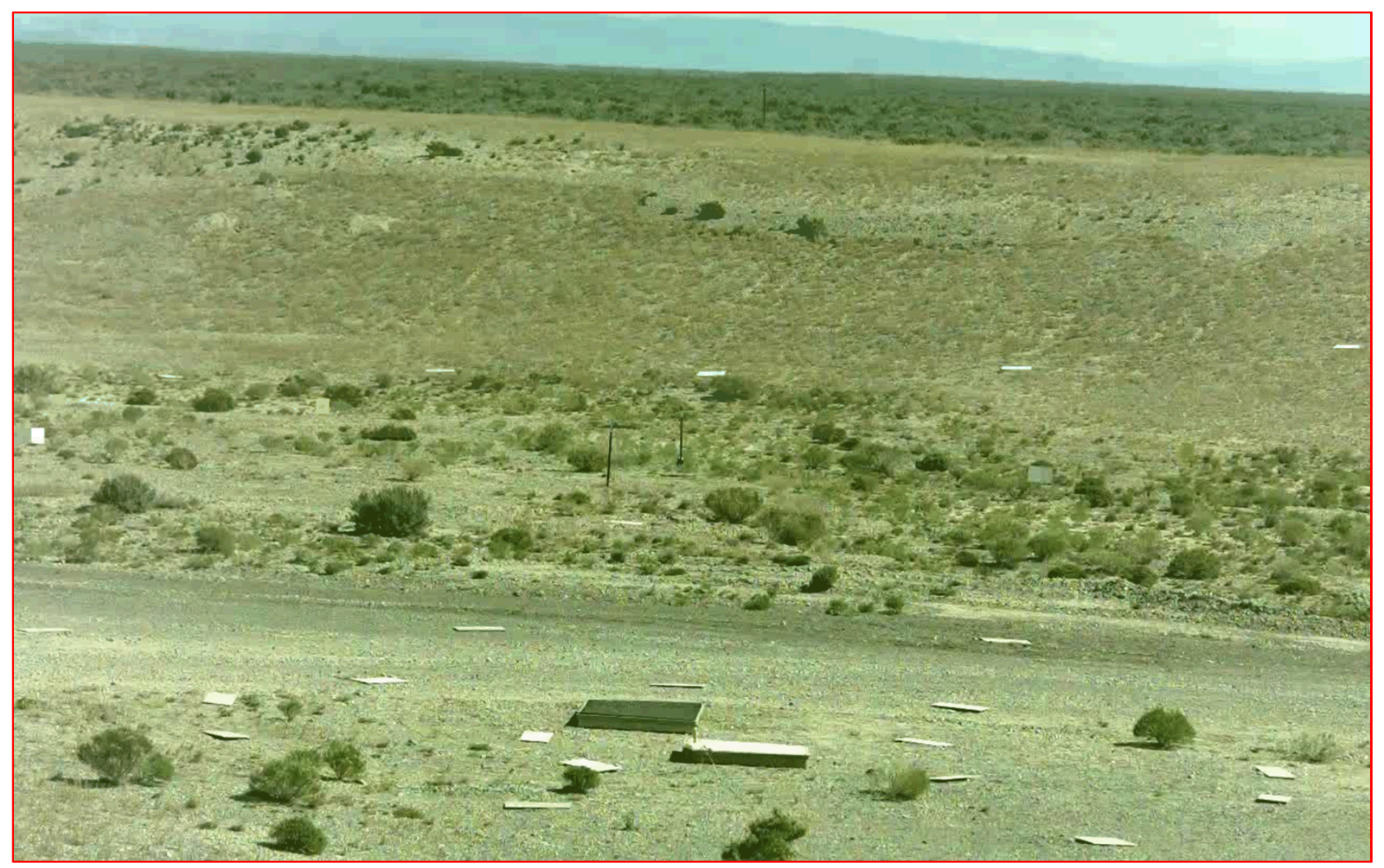




\section{Detonation - IR Imagery}




\section{Ground Zero Hot Spot vs Plume}

- Fire ball ground interaction create small radio active particles, $<10 \mu \mathrm{m}$, that deposit within 100 meters. Large particles, 100 to $300 \mu \mathrm{m}$, disperse further around ground zero, while larger fragments, $>1 \mathrm{~cm}$, are blasted out 100 to 300 meters into the near field

- The hot spot is enhanced when the fire ball interacts with loose dirt, and is reduced when it interacts with a hard surface, and the amount of dirt entrained into the fireball is inversely correlated with the amount of combustion/temperature

- A significant amount of material, up to $20 \%$, can be deposited in ground zero causing a radiological "hot spot"

- Radius of hot spot is about 4 times the size of the fire ball

- Hot spot produces "shine", deposition of radioactive material is between 2-4 orders magnitude higher than the near field plume deposition

- Plume deposition outside of the near field is a respiratory hazard, $<10$ $\mu \mathrm{m}$, and will take the path of least resistance

- Vertical surface deposition tends to $>100 \mu \mathrm{m}$ 


\section{After burn and Fireball Comparisons}

Steel Plate on the ground

On grass

Steel Plate, 1 meter high

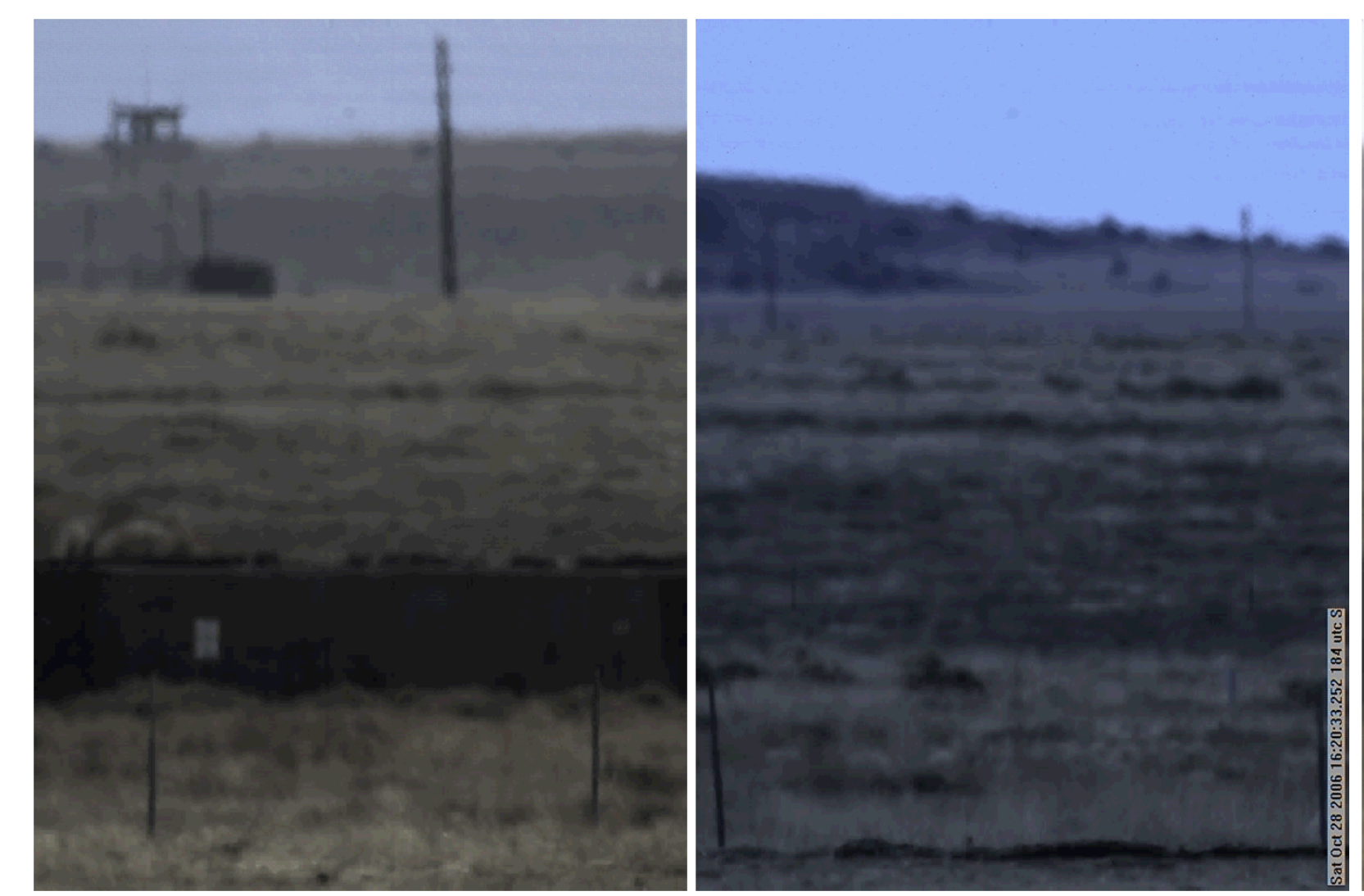




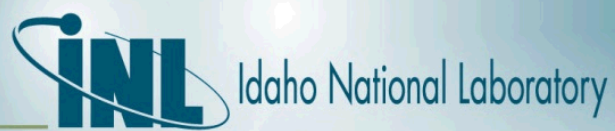

\section{Examples of Plume Behavior}
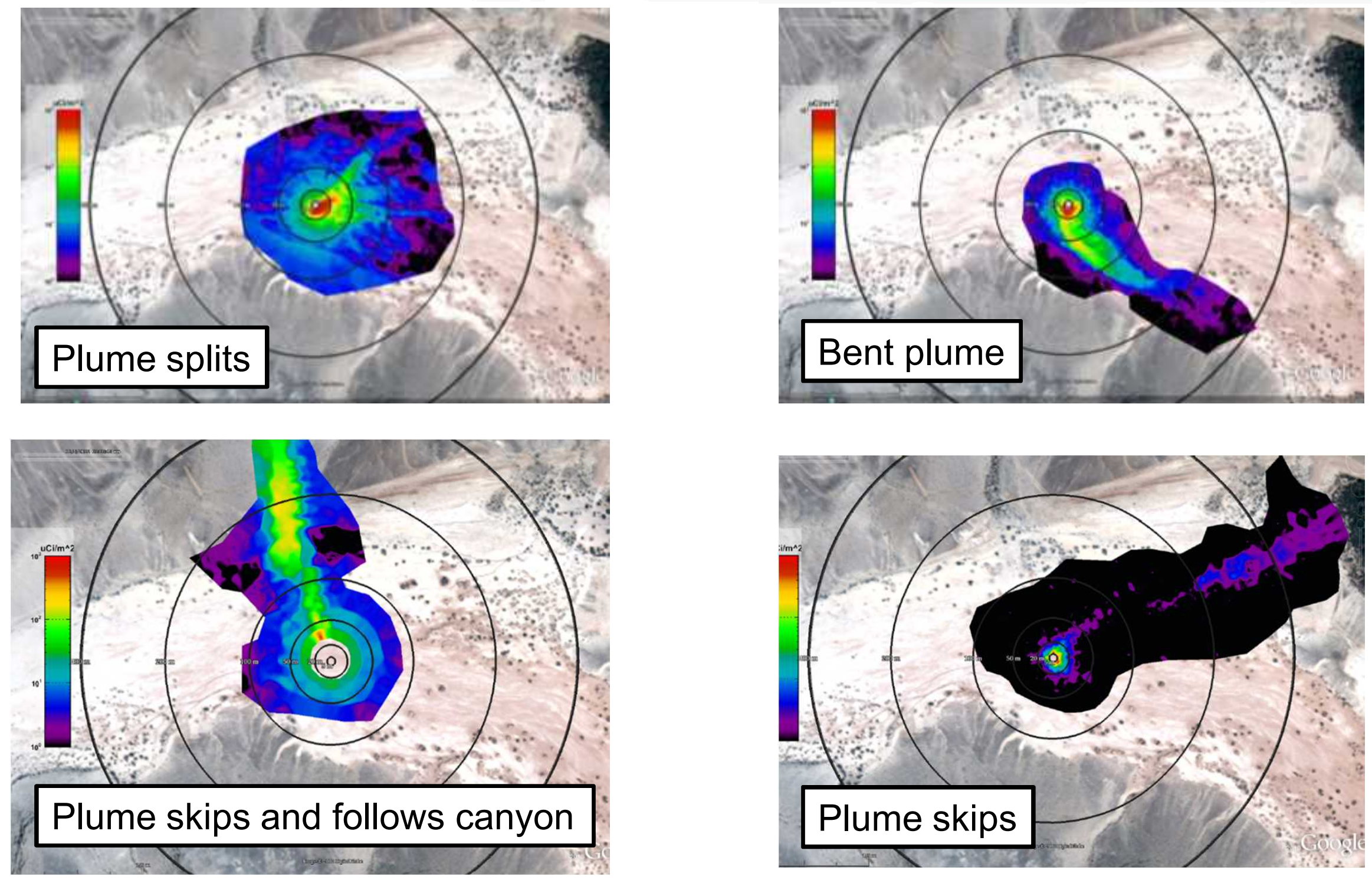


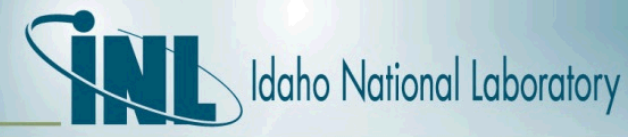

\section{DHS S\&T: First 100 Minutes Post RDD Detonation}

1. Initial Response \& On Scene Recognition: Safety Perimeter

2. Confirm Presence of Radiation: 2 readings from 2 locations

3. Report RDD Incident

4. Characterization of Detonation Site (strike team 1) establish hot side

5. Transect downwind \& establish Centerline (strike team 2)

6. Establish Near Field (strike team 3) plume

7. If $\mathbf{1 K m}$ detection start $\mathbf{1 0}$ Point Survey (strike team 4/RAP)

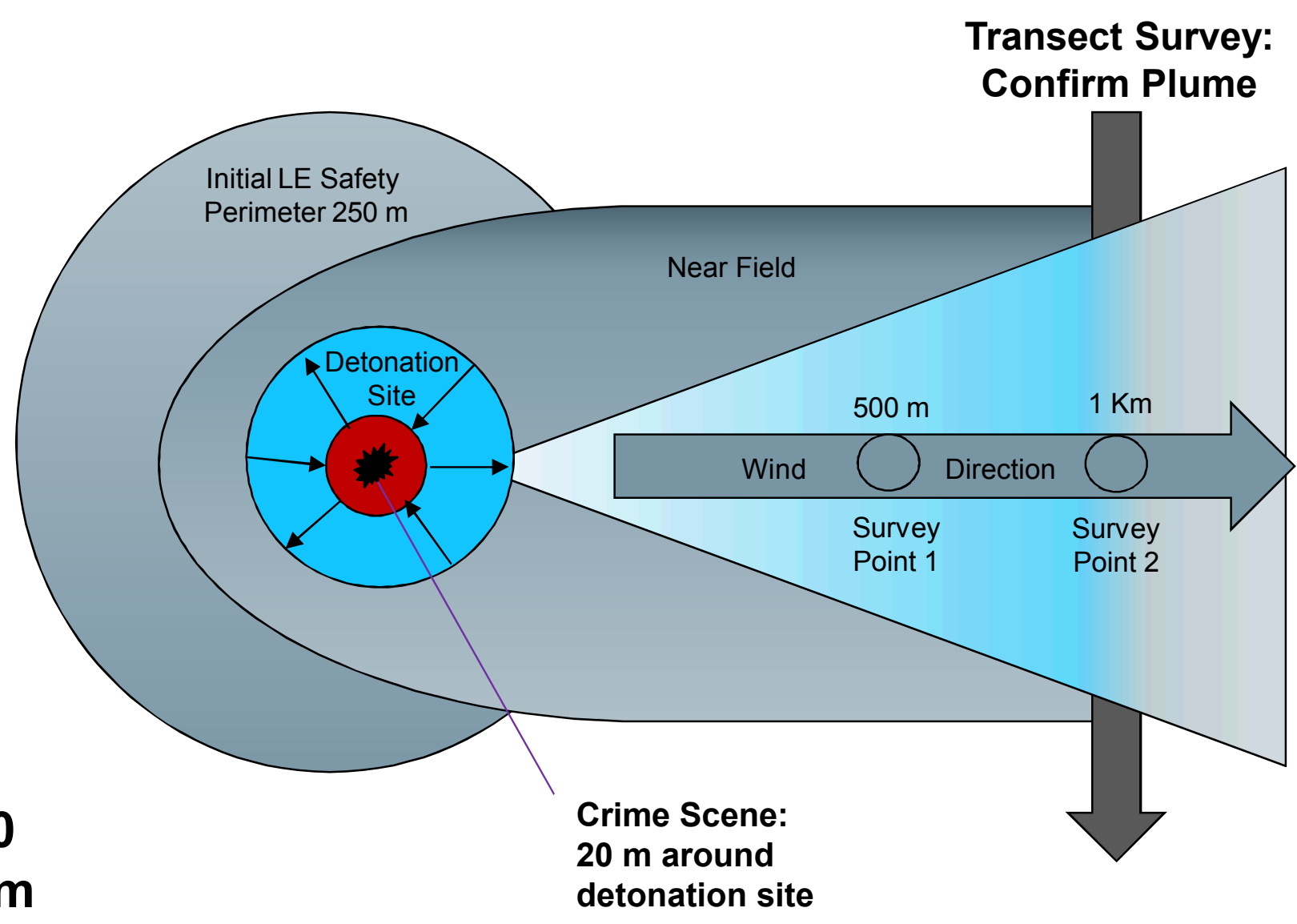




\section{DHS S\&T: First 100 Minutes Post RDD Detonation}

Initial Response \& On Scene Recognition

- Upon a suspected RDD event LE establishes $250 \mathrm{~m}$ Safety Perimeter, $20 \mathrm{~m}$ surrounding the detonation is a crime scene life saving rescue only

Confirm Presence of Radiation

- 2 readings from 2 locations using 2 different detectors

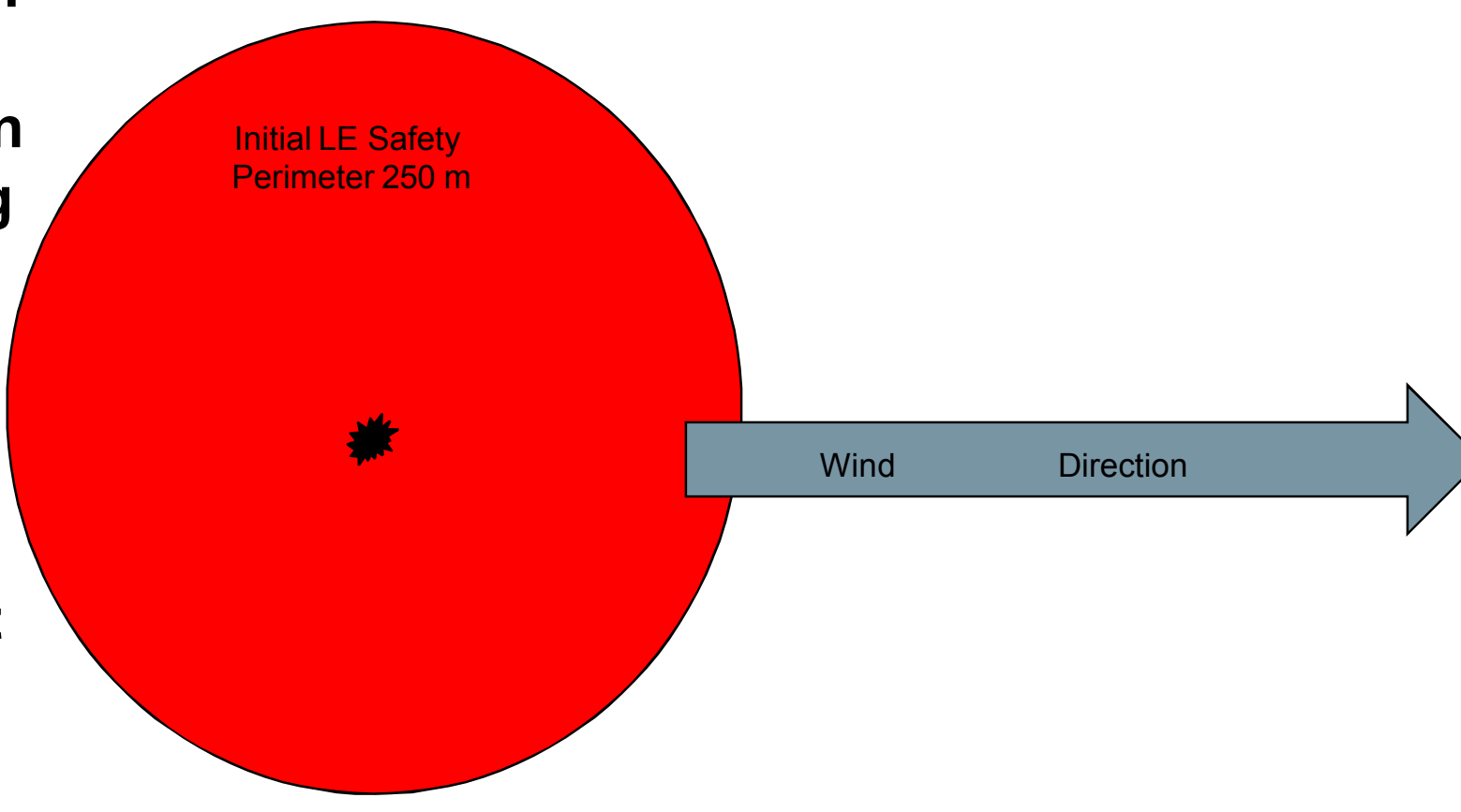




\section{DHS S\&T: First 100 Minutes Post RDD Detonation}

Report Notification of RDD Incident (state EMA, FBI, DOE, Command)

- First 10 minutes

The initial notification should include the following:

- Location of detonation

- Initial radiation and background readings

- ID Direction of plume (needed for HPAC and NARAC)

- Extent of damage \& casualties

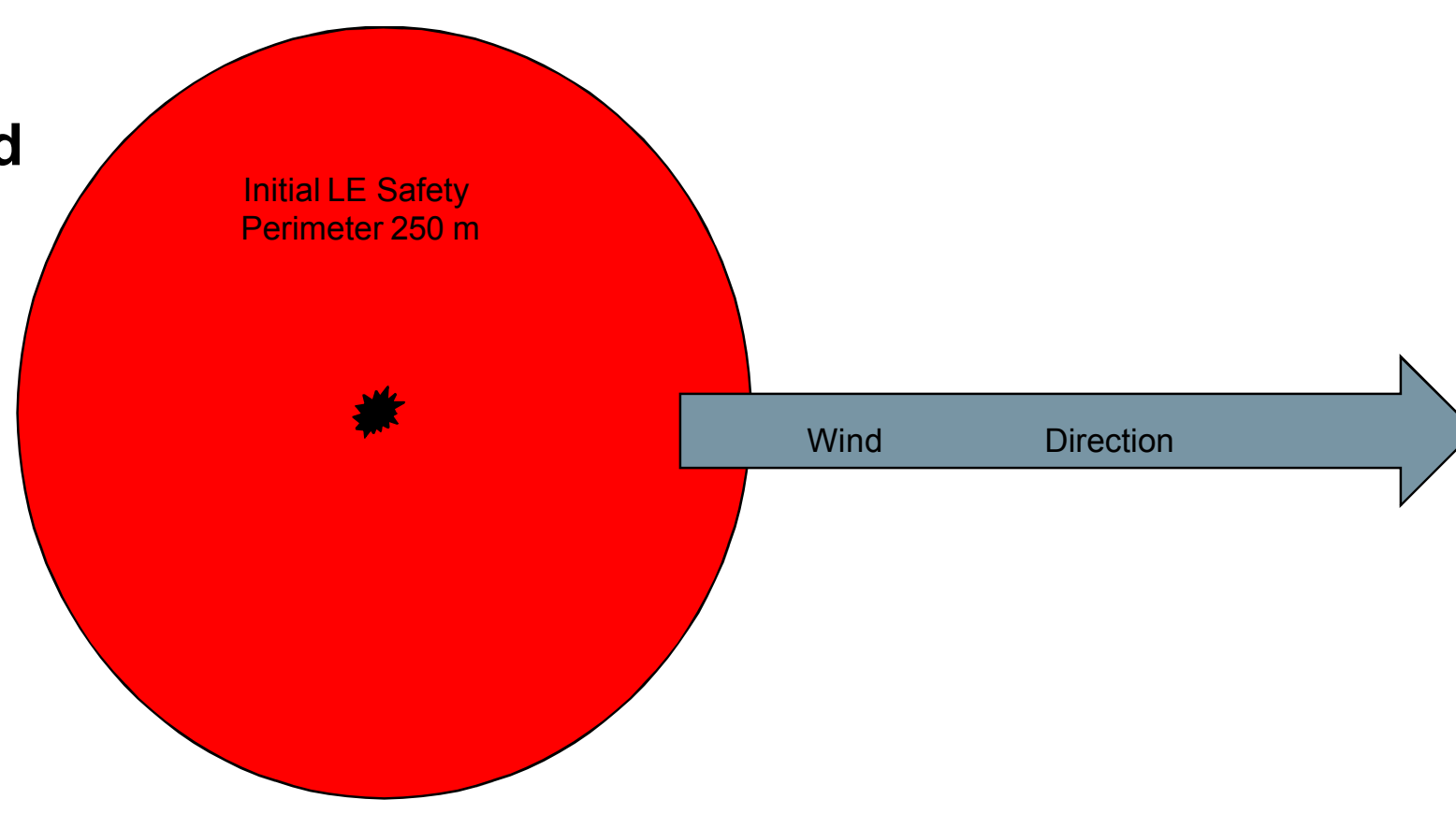

- Fires or other hazards on scene resulting from the explosion 


\section{DHS S\&T: First 100 Minutes Post RDD Detonation}

Characterization of Detonation Site (strike team 1)

- Responsible for estimating general direction/magnitude of contamination and rule in/out alpha contamination

- Clover leaf, what is the hot side?

- ID hot spot/zones

Direct next team to transect

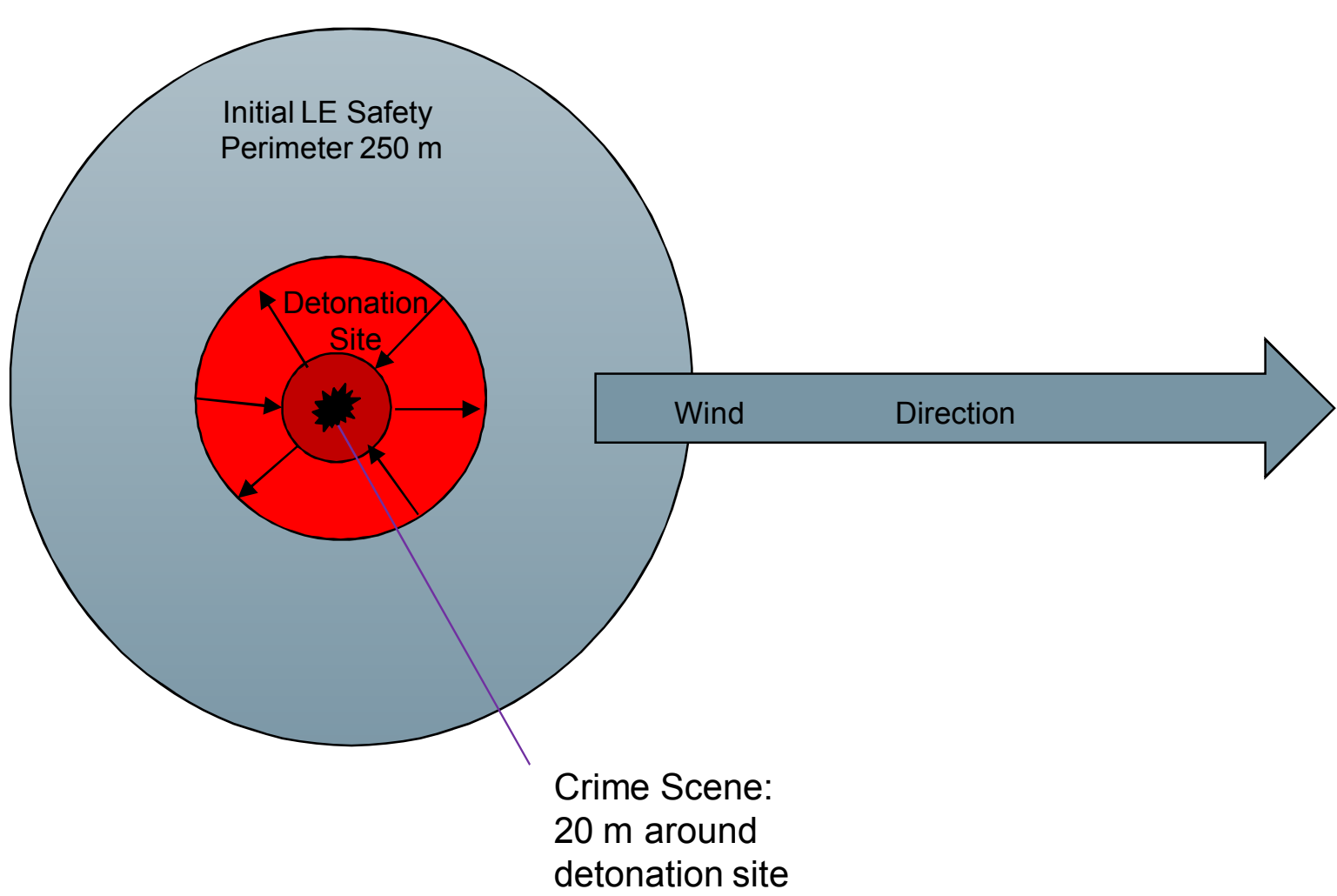




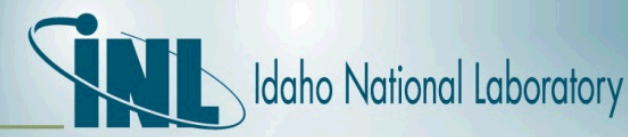

\section{DHS S\&T: First 100 Minutes Post RDD Detonation}

Transect downwind \& establish Plume Centerline (strike team 2)

- Strike team 1 hot side needed to send $2^{\text {nd }}$ team

- DHS Guidance1 Km

- Find the center line

- If no significant

- readings do we have a "smoke plume"?

- Third team deploys to connect the hot side to the centerline

- Cut the distance in half and confirm the centerline

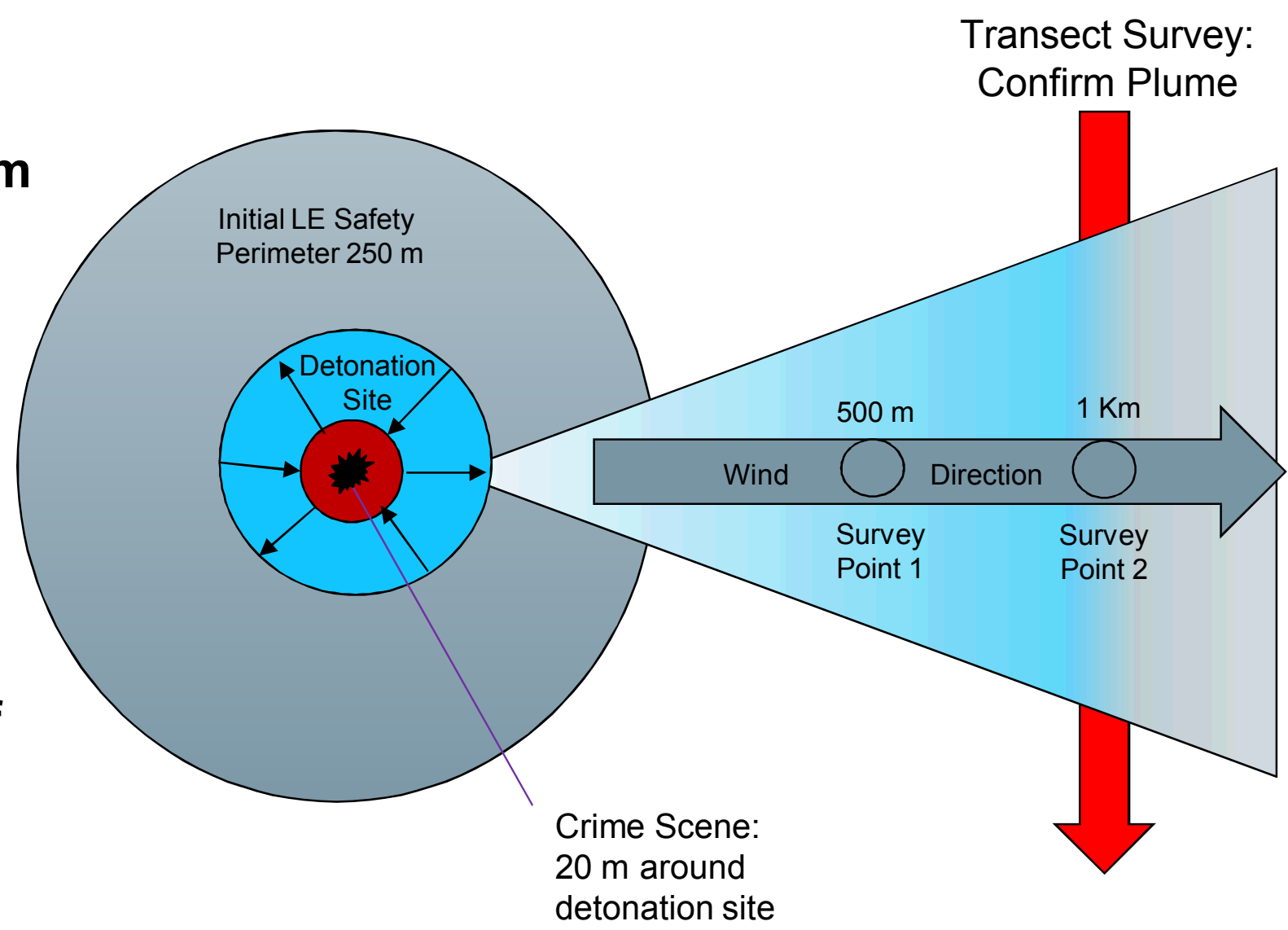




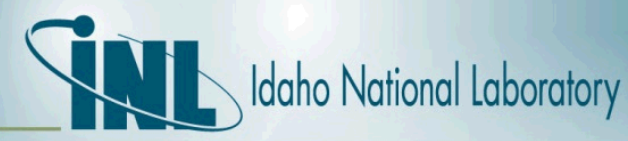

\section{DHS S\&T: First 100 Minutes Post RDD Detonation}

\section{Establish Near Field w/}

Hot Zone boundaries at 10 $\mathrm{mR} / \mathrm{hr}$ (strike team 3)

- Connect the hot side to the center line at the transect

- Map the plume by "mowing the grass"

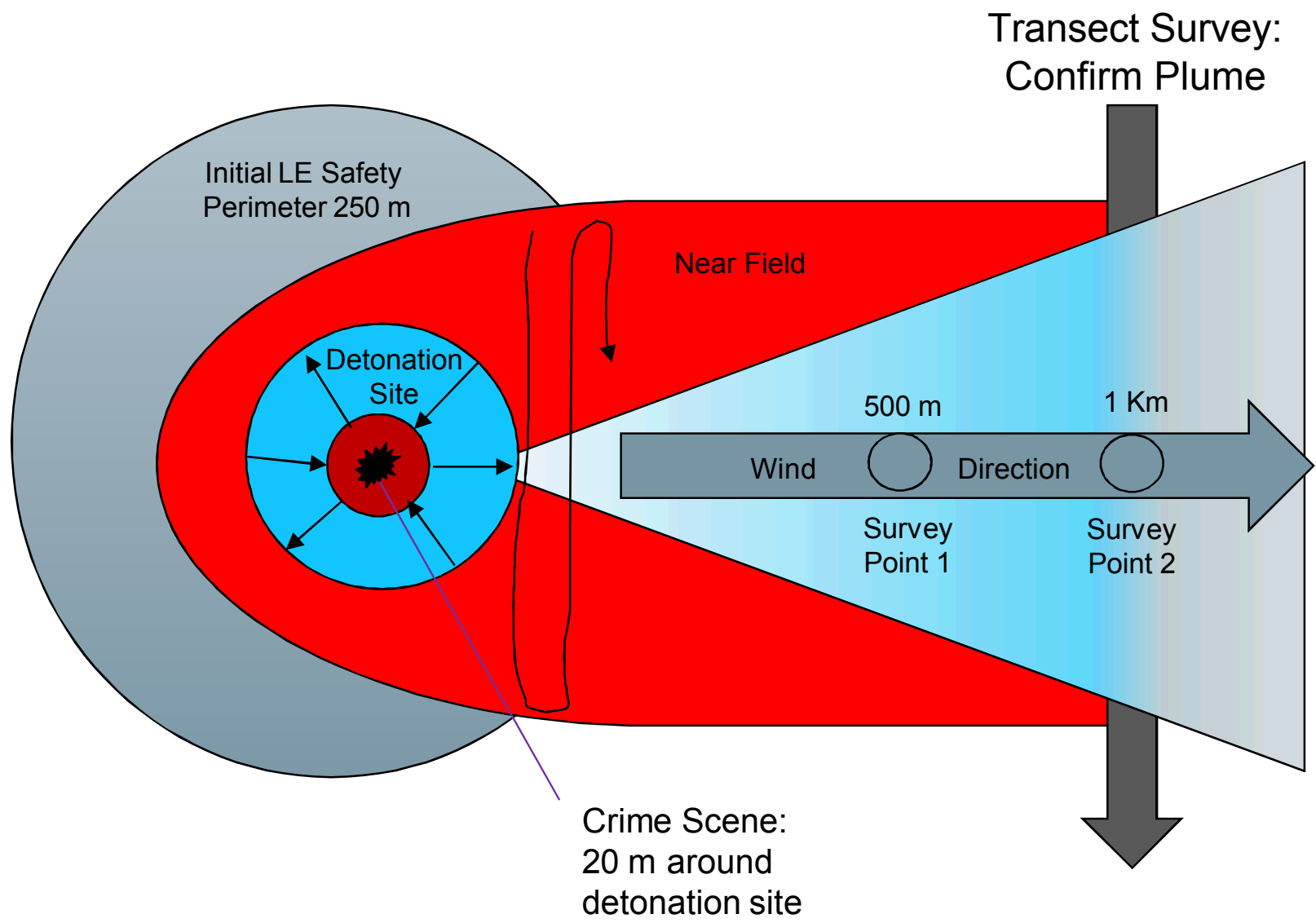




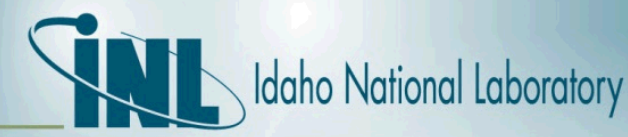

\section{Point Survey}

- Transect and Near field provide first 2 points (Phase I)

- Additional 8 points (Phase II) measurement at 1 meter, and measurement ground level, with GPS location

- Not a rigid template, close is OK

- $5 \mathrm{Km}$ is 3.2 miles

- Off-centerline plots at $22.5^{\circ}$ azimuth

MPDS can produce a "Heat Map" of the plume

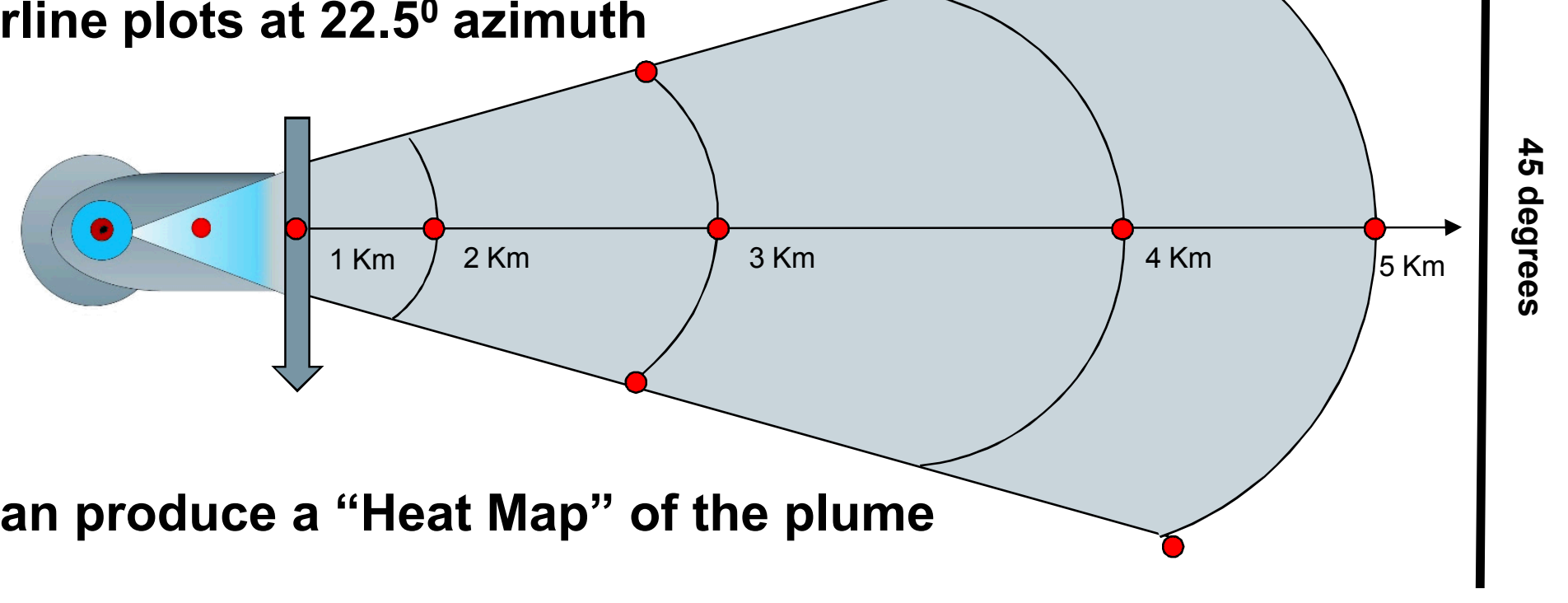

RadResponder data sharing and overlay templates, data from RadResponder can be used to adjust the NARAC plume plot 


\section{Questions?}

